\title{
Study of Optimizing Pension Mechanism Improvement Measures Based on Fuzzy Evaluation Model
}

\author{
Qingshuang $\mathrm{Ma}$ \\ Personnel Division, Xichang College, Xichang, China \\ ma_qingshuang@126.com
}

Keywords:pension system; present situation analysis; aging; fuzzy evaluation; optimization

\begin{abstract}
The ageing population brings an extensive and profound influence to give the social economy and people life, aging problem has already become a major social problem, the aging population is accelerating in China, and the pension mechanism is the urgent demand of current development of Chinese socialism. The analysis of China current aging fundamental national condition, in the actual data to the urgency of excavating perfect Chinese pension system as well as the current nursing status are not optimistic, further using fuzzy evaluation method to optimize the pension mechanism's improvement measures, and to provide suggestions for the current concept of retirement and pension mechanism strategy.
\end{abstract}

\section{Introduction}

Under the economic reform and economic globalization, perfecting country social pension system is a destiny benefit's revolution for the future generations. Social insurance system is the core of the endowment insurance; endowment insurance is a social "safety net", the important content of constructing harmonious society, and the important premise of our country's economic development, and political stability. Our country economy is in transition; in recent years, our country aging population growth rate rises sharply, resulting in our social pension system has brought about a series of problems and challenges. The reform and perfect of our country social pension system is imperative. Perfect our country social endowment mechanism of pension system is helpful for our country economy development to offer stability mechanism, and to improve people's quality of life. Through the study of international social pension system researches as reference, to deeply discuss the foreign reform experience that can be drawn lessons from for our country [1,2]. From the status quo of analysis of social pension security system in China, our many years' social pension system reform practice course as a foundation, to discuss the existing problems in the development of social pension security system.

\section{Analysis of Chinese aging society current situation}

A.Chinese aging population age distribution

The aging of the population has given society economy and people life to bring an extensive and profound influence, so the aging problem has already become a major social problem. To meet the challenge of population aging, the urgent need of improving the pension mechanism. Compared with foreign countries, China is serious lag in this regard [3]. The United States has already begun gerontology research from the1930s, international association of gerontology was established in 40 times, which describes that gerontology is very long attracted their attention. According to the sixth national census in China, now over 60 years old have already amounted to 185000000, over 65 years old have close to 130000000. In 2000 to 2010, the sixth census of China population age distribution is shown in table 1.

In Table 1, over 65 years population had appeared to grow ceaselessly from 2000 to 2010, 88210000 people rose to 118930000 in 2010, its growth rate was apparent, the ratio of the population was also rising, $6.96 \%$ in 2000 rose to $8.87 \%$ in 2010 . Zhang Tiemei introduces that our country has some 6 provinces and cities into the aging condition. China is only an elderly population of more than 100000000 countries in the world, and older population of over 60 year's age is annual rate of 
more than 3\% that increases labor [4,5]. In 2011, our country elderly over 60 year's population has increased to 185000000. It is expected by 2015 that the elderly population will be achieved 221000000 , it will be achieved 243000000 in 2020, and there is almost an old man in every five.

TABLE I. THE SIXTH CENSUS OF POPULATION AGE DISTRIBUTION FORM 2000 TO 2010

\begin{tabular}{|c|c|c|c|c|c|c|c|}
\hline \multirow{3}{*}{ Years } & \multirow{3}{*}{$\begin{array}{c}\text { Total population } \\
\text { (Million) }\end{array}$} & \multicolumn{6}{|c|}{ Ages group } \\
\hline & & \multicolumn{2}{|c|}{ 0-14 Years } & \multicolumn{2}{|c|}{ 15-64 Years } & \multicolumn{2}{|c|}{ Above 65 years } \\
\hline & & Population & Ratio (\%) & Population & Ratio (\%) & Population & Ratio (\%) \\
\hline 2000 & 126743 & 29012 & 22.89 & 88910 & 70.1 & 8821 & 6.96 \\
\hline 2001 & 127627 & 28716 & 22.5 & 89849 & 70.4 & 9062 & 7.1 \\
\hline 2002 & 128453 & 28774 & 22.4 & 90302 & 70.3 & 9377 & 7.3 \\
\hline 2003 & 129227 & 28559 & 22.1 & 90976 & 70.4 & 9692 & 7.5 \\
\hline 2004 & 129988 & 27947 & 21.5 & 92184 & 70.9 & 9857 & 7.6 \\
\hline 2005 & 130756 & 26504 & 20.3 & 94197 & 72 & 10055 & 7.7 \\
\hline 2006 & 131448 & 25961 & 19.8 & 95068 & 72.3 & 10419 & 7.9 \\
\hline 2007 & 132129 & 25660 & 19.4 & 95833 & 72.5 & 10636 & 8.1 \\
\hline 2008 & 132802 & 25166 & 19 & 96680 & 72.7 & 10956 & 8.3 \\
\hline 2009 & 133450 & 24659 & 18.5 & 97484 & 73 & 11307 & 8.5 \\
\hline 2010 & 134091 & 22259 & 16.6 & 99938 & 74.53 & 11893 & 8.87 \\
\hline
\end{tabular}

B.Chinese elderly dependency ratio increasing

With the elderly population increasing and life extension, due to illness, disability, age, it will lose life ability in the elderly increase significantly, which will bring heavy burden for the country, society and family. On one hand, countries improve medical insurance, especially the elderly medical insurance is very important, at the same time; to improve our country endowment insurance system is very necessary [6]. The Ministry of health survey shows that there are histories of chronic disease in elderly population of $60 \% \sim 70 \%$, with the average 2 to 3 diseases. According to the Chinese aging research center survey, the older over 60 years has diseases in the remaining time, which are a number of chronic diseases, high cost and long time; these will bring the social economy to bring the greater burden. Chinese elderly population aged dependency ratio is shown in table 2.

TABLE II. CHINESE ELDERLY POPULATION AGED DEPENDENCY RATIO FORM 22000 TO 2010

\begin{tabular}{|l|l|l|l|}
\hline Years & Total dependency ratio $(\%)$ & Child dependency ratio $(\%)$ & Elderly dependency ratio (\%) \\
\hline 2000 & 42.55966 & 32.63658 & 9.92308 \\
\hline 2001 & 42.04599 & 31.96023 & 10.08576 \\
\hline 2002 & 42.24823 & 31.86419 & 10.38404 \\
\hline 2003 & 42.04515 & 31.3918 & 10.65336 \\
\hline 2004 & 41.00929 & 30.31654 & 10.69274 \\
\hline 2005 & 38.81121 & 28.13678 & 10.67444 \\
\hline 2006 & 38.26735 & 27.30782 & 10.95952 \\
\hline 2007 & 37.87422 & 26.77575 & 11.09847 \\
\hline 2008 & 37.36243 & 26.0302 & 11.33223 \\
\hline 2009 & 36.9 & 25.34247 & 11.64384 \\
\hline 2010 & 34.17416 & 22.27291 & 11.90125 \\
\hline
\end{tabular}

In table 2, the total dependency ratio of Chinese population has been reduced in ten years. The total dependency ratio has decreased from $42.55966 \%$ in 2000 to $34.17416 \%$ in 2010 ; the child dependency ratio has decreased from $32.63658 \%$ in 2000 to $22.27291 \%$ in 2010; the elderly dependency ratio has increased from $9.92308 \%$ in 2000 to $11.90125 \%$ in 2010 . In China, there generations situation is widespread, most of the family demographic structure is "four two one" and "four two two" type, there exist four generations together, so the young is few, and the elderly is many situations, the ability of family support for the elderly is weakened, which need social 
endowment to make up the family endowment [7,8]. From 2000 to 2010, Chinese elderly population aged dependency ratio chart is shown in Figure 1.

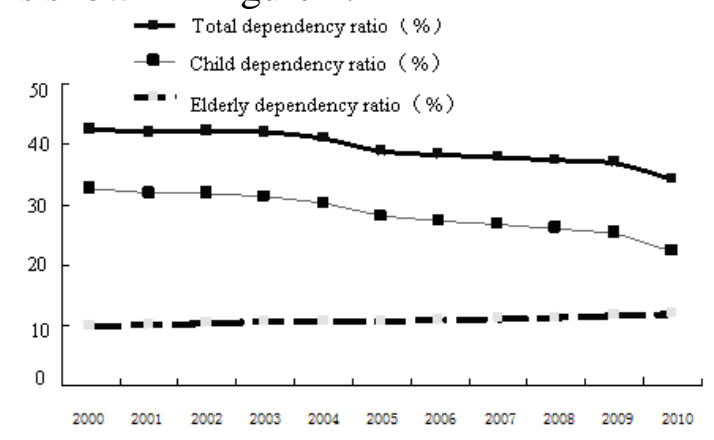

Figure 1. Chinese elderly population aged dependency ratio chart from 2000 to 2010

In Figure 2, the total dependency ratio in China showed a downward trend between 2000 and 2010; the child dependency ratio also showed a downward trend, however the elderly dependency ratio showed a rising trend. It is clear that China begins to present rapid population aging, and elderly dependency ratio increasing, China has been thought that the population aging is one of the fastest in worlds. In the long term, with the population aging, the elderly people always increase in general population, labor population proportion will reduce.

\section{Analysis of China endowment mechanism present situation dilemmas}

A.Imperfect enough endowment insurance policy

In China, the rural elderly have been over 60 years of age that have subsidized to 55 Yuan per month, however for the present situation of our country, some childless elderly, incompetent elderly and frail elders are not much, the old-age insurance system does not classify policy formulation and policy refinement for these special populations. In fact, this part of the nursing situation is most serious. And the state had issued a "town enterprise workers' basic old-age insurance relations shift continuation interim measures" in December 28, 2009. From January 1, 2010 onwards, whether the insured person are urban workers and migrant workers' employment, its basic old-age insurance relations and pay endowment insurance premiums may be required to transfer, how to receive the rules will be not refined in the receiver place, forming each its politics, it will led to damage the interests of the people. In conclusion, policy classification and thinning should be further improved [9].

B.Nursing institutions’ awkward position

According to statistics, China has provided 3140000 beds by the end of 2011, an average of 1000 old men have only 17 beds, which are lower than the proportion of 5\%-7\% in the developed country, and are also below the level of $2 \%-3 \%$ in developing countries. However in fact, only two million five hundred thousand beds are being used, hundreds of thousands of beds are in the idle state. On one hand, all clamoring to increase the old bed, another hand having a lot of beds is been idle condition. Now the nursing homes basically have two kinds of pattern: government-run and nongovernment-run. After investigation, the state subsidies to set high for the government-run and have fully equipped, people queue to go to pension. However non-government-run is the emergence of a large number of idle beds because of inadequate investment.

C.Responsibility deficiency of local governments in the endowment

Government also has introduced the relevant policies on the elderly pension. However from the current situation, the old people receive pensions that are only national subsidy of 55 Yuan, local finance are basically unable to bear. Because of China's new social insurance started late, so that the part of personal commitment is almost no effect. Therefore, countries should increase financial input in the elderly. Of course, at the same time, the government should perfect the endowment of supervision mechanism, avoiding only saying, no practice and inadequate implementation of happens. In ninety times, nation had been the implementation of "farmer Paul ", however it was ultimately having a beginning but no end.

D.Elderly people with low income

Now, China is old before getting rich, and does not think of first old situation that is more serious. Existing over the age of six 60 old men are from villages, only little people live in the town. Rural 
old man is without any economic security, a part of the elderly in the urban has pension, because the partly elderly is without fixed organs, business or business units to rely on, after retiring, they can only receive a certain retirement pension from the social security administration, however a part of the amount is relatively small, and even some can only rely on subsistence allowances life.

\section{To improve measures of optimization pension mechanism}

\section{A.Response measures of the aging pension status quo plight}

In the of analysis Chinese aged pension difficult situation, the influence of nursing perfect mechanism factors are not perfect endowment insurance policy, the old institutions in the awkward position, lack of responsibility in local government pension, the elderly low income and so on. The main element index set of definition the influence of nursing mechanism is $M=(M 1, M 2, M 3)$; the corresponding weights set is $\mathrm{A}=(\mathrm{A} 1, \mathrm{~A} 2, \mathrm{~A} 3)$; definition the pension mechanism perfection factor layer index set is

$$
M_{k}=\left(M_{k_{1}}, M_{k_{2}}, \ldots ., M_{k_{n}}\right) ;(k=1,2,3)
$$

In the corresponding weights, it can be clearly endowment mechanism implementation; in optimizing pension mechanism perfecting measures, to define the evaluation result set that is $\mathrm{W}=$ $\left(W_{1}, W_{2}, W_{3}, W_{4}\right), W_{j}(j=1,2,3,4)$. When $j=1,2,3,4$, they are respectively excellent, good and poor of the evaluation result. From $M_{k}$ to $W$, the fuzzy evaluation matrix is $R_{k}$, where $r_{i j}(i=1,2, \ldots, s ; j=1$, $2,3,4)$ is said as $W_{j}$ conformity assessment of the $j$-th evaluation results by the pension mechanism improvement factor index $X_{k i}$. Finishing scale, the index $L_{k i}$ has $W_{1}$ grade evaluation results in $W_{\mathrm{il}}$, the $\mathrm{W}_{\mathrm{i} 2}$ has $\mathrm{W}_{2}$ grade evaluation results, the $\mathrm{W}_{\mathrm{i} 3}$ has $\mathrm{W}_{3}$ grade evaluation results, and the $\mathrm{W}_{\mathrm{i} 4}$ has $\mathrm{W}_{4}$ grade evaluation results, then the $i=1,2, \mathrm{~L}, s$ has:

$$
r_{i j}=\frac{W_{i j}}{\sum_{j=1}^{4} W_{i j}}
$$

The evaluation matrix $R_{k}$ of pension mechanism improvement factor index $M_{K i}$ as fuzzy arithmetic, it can get the main factors index $\mathrm{M}_{\mathrm{K}}$ for vector $\mathrm{F}_{\mathrm{K}}$ of evaluation result set $\mathrm{W}$ with.

$$
\begin{aligned}
F_{K} & =A_{K} \cdot R_{K}=f_{K_{1}}, f_{K_{2}}, f_{K_{3}}, f_{K_{4}} \\
R & =\left[\begin{array}{l}
F_{1} \\
F_{2} \\
F_{3}
\end{array}\right]=\left[\begin{array}{llll}
f_{11} & f_{12} & f_{13} & f_{14} \\
f_{21} & f_{22} & f_{23} & f_{24} \\
f_{31} & f_{32} & f_{33} & f_{34}
\end{array}\right]
\end{aligned}
$$

Then, to carry out fuzzy transform for the R, it can obtain the pension mechanism perfect index M. The membership vector $\mathrm{F}$ of comment set $\mathrm{W}$ is:

$$
F=A \cdot R=\left[a_{1} a_{2} a_{3}\right] \cdot\left[\begin{array}{l}
F_{1} \\
F_{2} \\
F_{3}
\end{array}\right]=A \cdot\left[\begin{array}{lll}
A_{1} & R_{1} \\
A_{2} & R_{2} \\
A_{3} & R_{3}
\end{array}\right]=\left[f_{1} f_{2} f_{3} f_{4}\right]
$$

In formula (5), it is a fuzzy comprehensive evaluation model of optimizing the pension mechanism perfection measures; through the model, it can obtain that strengthening the endowment policy should be in the formulation of policy in countries, , at the same time to supervise mechanism and aggrandizement country in the nursing process plan, control, supervision functions; increasing the national new agricultural insurance basis pension allowance base, the standards of state financial subsidies increase with the age, the pension amount is also increased pension by the state, collective and individual; increasing pair of civilian pension agency support, government investment equipment and facilities, by way of bidding operator management selection of pension institutions; on the private pension agency to give some preferential policies, such as land, taxation, subsidies, to try to provide some favorable conditions.

B.To create a diversified pension mode

The establishment and improving social security system of the level of socio-economic development is not only an important guarantee of social stability and the stability of the state, but also is inevitable requirement of economic society coordination for achieving sustainable development. At present, China is a period of rapid development in the primary stage of socialism, and the old social security system has gradually been newly replaced established social security 
system. Under the system of planned economy, a lack of social security problems should not be ignored. In the course of the establishment of a new system, many new social contradictions continue to appear, to make our country faces grim and complex condition. To increase propagandist strength, let people to actively participate in old-age industry construction, adopting diversified pension. According to the local actual situation, to take the community nursing mode, so that old people have a mind mutual consolation, physical fitness places, suitable for carrying out the old features entertainment, sports, education, popular science activity; to take the younger elderly and the aged old man twinning way; follow the example of Hongkong and other places to establish " time bank " system, with adult period of spare time for the elderly to provide services, the service time is recorded and stored to the time savings bank, until retired after extracted from the corresponding time of labor; to encourage commercial pension insurance institutions to introduce some effective insurance scheme; trying to some fixed assets as collateral way to solve the problem of old-age care.

\section{Lecture Notes in Computer Science in the ISI SCI Expanded}

Social security is one of most important social economic system in the modern country, which is closely related with economic development, and is also the important sign of social progress and social civilization.

On the perfect and reform of social pension security system, it has put forward new problems to be solved and long-term planning of the requirements of sustainable development, to study the social pension security system in China needs to sort out the basic theory and the value orientation of institutional policy, in order to better guide our country social security system reform, to make the sustainable development, and to China's economic development to provide a stable mechanism and enhance national quality of life, there can be economy long-term development and social harmony and stability.

\section{References}

[1] CCTV 2 sets. Economic a half hours: Tomorrow how nursing, August 20, 2012.

[2] Yang Guiling. Thinking of improve China's endowment insurance system [J]. Taxation and economy, 2010: 67-68.

[3] Tang Zizheng. Thinking of the current China's rural endowment insurance legal system perfection [J]. Law Journal, 2010 (3): 123-124.

[4] Wang Fang. Rural social endowment insurance-the construction of harmonious society needs to crack problem [J]. Social security system, 2009(10): 156-157.

[5] Zhang Na. Thinking of rural social endowment insurance legislation [J]. Journal of Hubei Economics University, 2009(7): 35-36.

[6] Zhang Xinmin. Thinking of perfect and innovation of social insurance fund supervision system [J]. Social security system, 2009(9): 145-146.

[7] Li Layun. Legislative thinking of China's rural social endowment insurance in the new rural construction [J]. Journal of Hunan university of commerce, 2009(13): 78-79.

[8] Fujita Masaku, Paul Krugman. Spatial Economics - City, regional and international trade [M]. Renmin University of China press, 2011(2):312-332.

[9] Baldwin. Richard E et al. Economic geography and public policy[M]. Princeton University Press, 2009: 435-456. 